Conference Article

\title{
Physical Modelling as a Method to Estimate Plastic Flow Homogeneity During ECAP
}

\author{
S.N. Faizova ${ }^{1 *}$, G.I. Raab ${ }^{1}$, D.A. Aksenov ${ }^{2}$, I.A. Faizov ${ }^{3}$, N.G. Zaripov ${ }^{1}$, V.I. Semenov ${ }^{1}$ and R.A. Faizov $^{1}$ \\ ${ }^{1}$ Ufa State Aviation Technical University, Ufa, Russia \\ ${ }^{2}$ Institute of Molecule and Crystal Physics Ufa Research Center of Russian Academy of Sciences (IMCP URC RAS), Ufa, Russia \\ ${ }^{3}$ Bashkir State University, Ufa, Russia
}

Received 15 September 2014; Accepted 20 September 2014

\begin{abstract}
A physical model method allows the estimation of the strain inhomogeneity in a material subjected to equal channel angular pressing. Copper samples which deformed with ECAP with a standard die-set showed significant inhomogeneity. The sample section was split into two sections, which have significantly different values of accumulated strain and, as a consequence in the microstructure. Application of a die-set with a special geometry modification allows uniform strain across the sample. A comparative analysis of physical modeling results, changes of microstructure and properties showed complete correlation. Known theoretical models of the ECAP process with deformation modes close to simple shear are analyzed.
\end{abstract}

Keywords: equal channel angular pressing, ECAP, inhomogeneous deformation, copper, microstructure, strain hardening

\section{Introduction}

Equal channel angular pressing (ECAP) is one of widely used methods for crystal structure refinement to submicrometer and nanometer sizes in bulk billets, as it enhances material properties [1-6]. Structure refinement during ECAP occurs through the self-alignment of the dense dislocation pile-ups produced by the process at the lowangle and high-angle boundaries [3, 7]. Strain inhomogeneity produces inhomogeneity in microstructure and, as a consequence, of material properties. In numerous studies strain inhomogeneity is linked to the die-set geometry and the properties of the deformed material [8-12]. In [11] numerical modelling showed that the corner gap formation and lower strain at the outer part of the sample were associated with strain rate hardening. A rounding of the outer angle at the channels intersection causes strain inhomogeneity even in ideally plastic materials. In [8] it is shown that for pure $\mathrm{Al}$ a change in the outer angle rounding by about $20^{\circ}$ does not lead to significant change in properties.

In this work strain inhomogeneity in M1 copper billets during the first ECAP pass with a standard die-set is studied. The possibility of producing fairly uniform strain by modifying the die-set is shown. The degree of strain inhomogeneity was estimated at different length scales by studying material structure and indirectly with microhardness measurements.

\footnotetext{
*E-mail address: snfaiz@mail.ru

ISSN: 1791-2377 @ 2014 Kavala Institute of Technology. All rights reserved.
}

\section{Material and experimental procedures}

Commercial pure copper M1 billets of $8 \times 8 \times 60 \mathrm{~mm}$ after 1hour annealing at $600^{\circ} \mathrm{C}$ were used. ECAP was carried out at room temperature at a ram speed of $7 \mathrm{~mm} \cdot \mathrm{s}^{-1}$. In addition to a standard ECAP die-set with an angle of channels of $90^{\circ}$ (Fig. 1), a modified die-set was used, with a local recess 0.2 $\mathrm{mm}$ deep and $4 \mathrm{~mm}$ wide at an edge slope of $\Omega=15^{\circ}$, which was formed at the bottom of the output channel with a radius $\mathrm{R}=2 \mathrm{~mm}$ (Fig. 2). It should be noted that the section of the output channel is equal to that of the input channel. The modified die geometry was optimized with FEM calculations described previously [13 14].

The grid method was used to study macroscopically the metal plastic flow. The billets were cut in the longitudinal direction. On the inside surface of one of the halves a rectangular grid $2 \times 2 \mathrm{~mm}$ was scratched with a thin metal needle. As grid lines parallel to the longitudinal axis may provide less information, there were cases where only transverse scratches were drawn. Then the billet with the grid was joined again comprising of the two halves. In the billet's main part, ignoring the end sections, the effective local strain $\varepsilon$ (Fig.1 and formula (1) $[2,15]$ ) after ECAP will be

$$
\varepsilon=\frac{1}{\sqrt{3}} \cot \alpha
$$

where $\alpha$ is the angle that transverse scratches form with the longitudinal axis. 


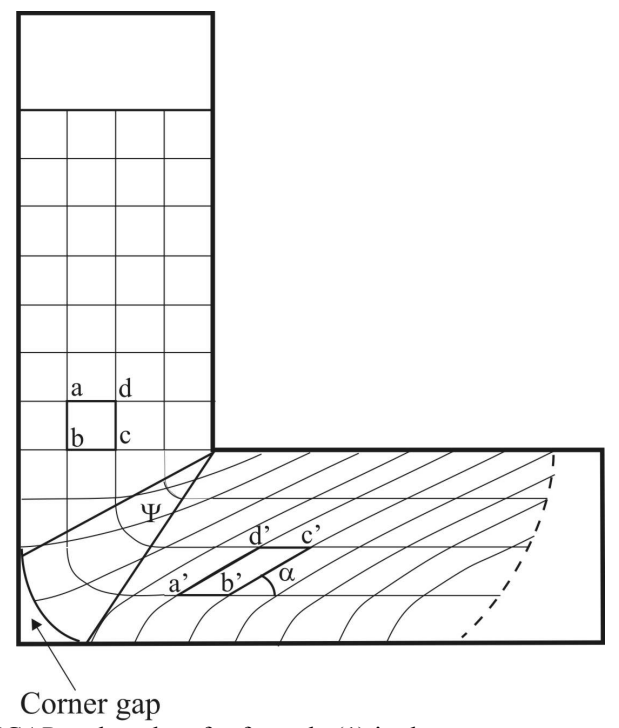

Fig. 1. ECAP and angle $\alpha$ for formula (1) in the text.

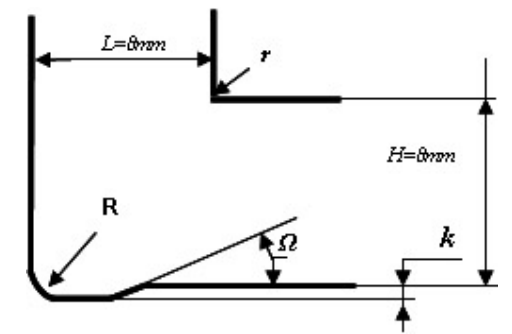

Fig. 2. Design of a different ECAP die-set with a recess at channels intersection. $\kappa$ - recess depth, $\Omega$ - edge slope angle

The structure of the copper billets was studied at different scales using an optical microscope. In order to get a comprehensive picture of the material structure after ECAP, panoramic photo of the central part of a sample was taken. Microhardness measurements at a distance of $0.5 \mathrm{~mm}$ between them were taken with a microhardness tester «Micromet-5101» under a load of 100 gram and a dwell time of 10 seconds.

\section{Results and discussion}

The copper billets initially had an equiaxed structure with an average grain size of about $90 \mu \mathrm{m}$ and a large number of annealing twins typical of copper.

Figs. 3 (a-c) and 4 (a-c) show the longitudinal sections of billets after one ECAP pass with the standard and modified die-sets, respectively.

The square grid cells in the upper part of the piece in $75 \%$ of a sample thickness are shaped like skewed parallelograms with an angle, $\alpha$, to the longitudinal axis of about $28^{\circ}$, the result of strain from (1) of $\varepsilon=1.1$. In the lower part of the section the angle $\alpha$ is much larger, as the strain in this area is much lower than in the upper part. (Hereinafter these areas will be referred to as I and II.) Thus, strain is inhomogeneous across the sample.

For the modified die-set the angle of transverse scratches to the longitudinal axis is the same through the thickness of the sample, close to $32^{\circ}$ (Fig. 4 , a). The average strain value from (1) is equal to 0.9 .

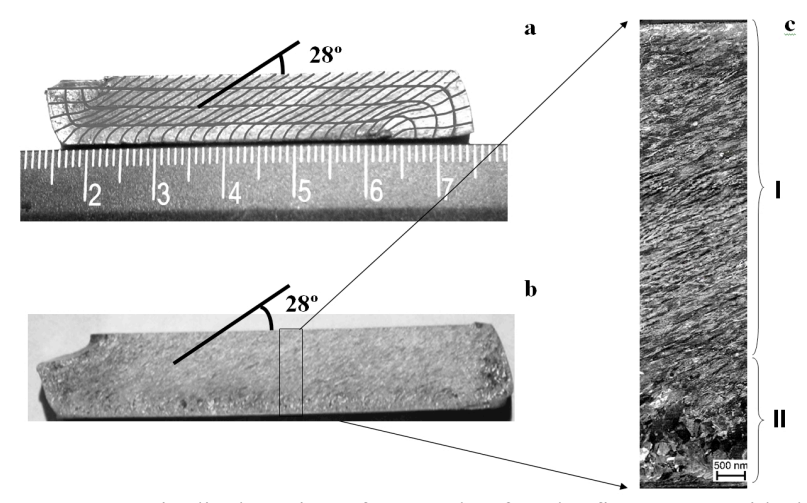

Fig. 3. Longitudinal section of a sample after the first ECAP with the standard die-set. After the 1st pass: a - deformed grid ; b macrostructure, $\mathrm{c}-$ microstructure.

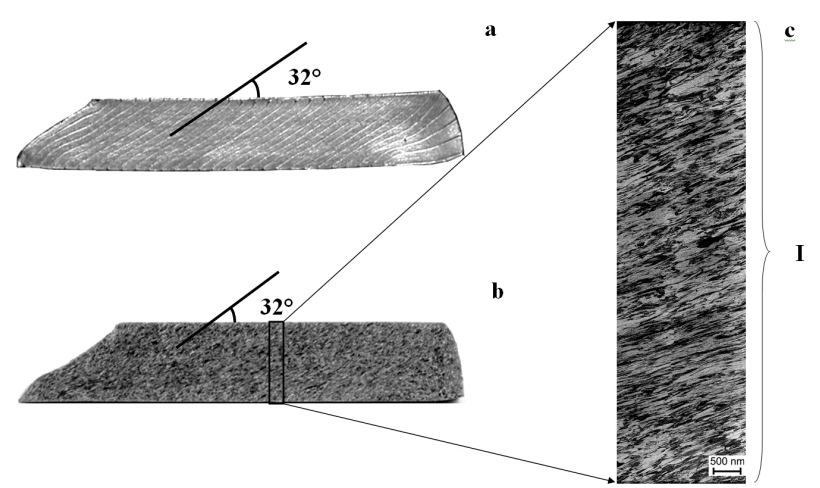

Fig. 4. Longitudinal section of the samples after the first ECAP pass on the modified die-set. a - grid method; b - macrostructure, c mesostructure

The macro- and micro-structure of the samples after ECAP with a standard die-set correlate well with the results obtained by the grid method (Fig. 3, b and c). Two areas can be clearly identified in Fig. 3 c. A metallographic texture with elongated grains is observed in the main part that corresponds to area I. The long axes of grains are inclined at an angle of $28^{\circ}$ to the longitudinal axis of the sample. Higher magnifications show shear bands at an angle close to $45^{\circ}$ to the longitudinal axis of the sample (Fig. 5, a - white arrows). In the lower part (area II) practically equiaxed grains are observed, their size is close to the initial one (Fig. 3, c).

In the samples processed with the modified die-set (Fig. 4, c), a metallographic texture with elongated grains located at an angle of $32^{\circ}$ to the longitudinal direction is observed after the 1 st pass. Fig. 5, b displays the same structure at higher magnification. One may observe local shear bands within separate grains. However, unlike the samples processed with the standard ECAP die-set, there are no traces of a macroscopic shear cross through the sample.

The microhardness distribution across the samples produced with both die-sets showed full correlation with the structural changes. The microhardness of the samples after ECAP on the standard die-set was $1310 \pm 70 \mathrm{MPa}$ in area I, in area II it was $960 \pm 50 \mathrm{MPa}$. The microhardness distribution across the thickness of the cross section is uniform, and the average value is $1410 \pm 60 \mathrm{MPa}$.

During ECAP the deformation mode is closer to simple shear [2]. Two possible material flow pictures which assume uniform material flow speed are shown in Figs. 6 a,b. In the first case (Fig. 6,a) the deformation zone is localized in the plane of the channels intersection. If the flow speed is 


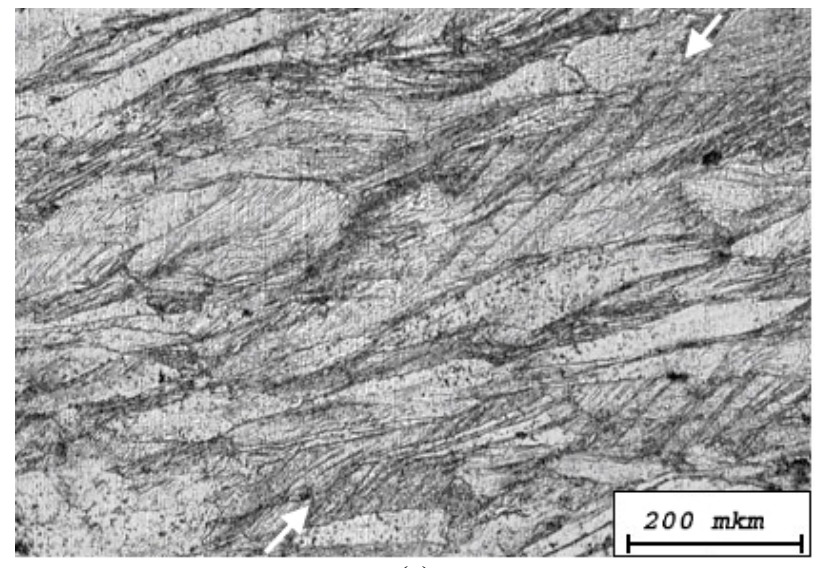

(a)

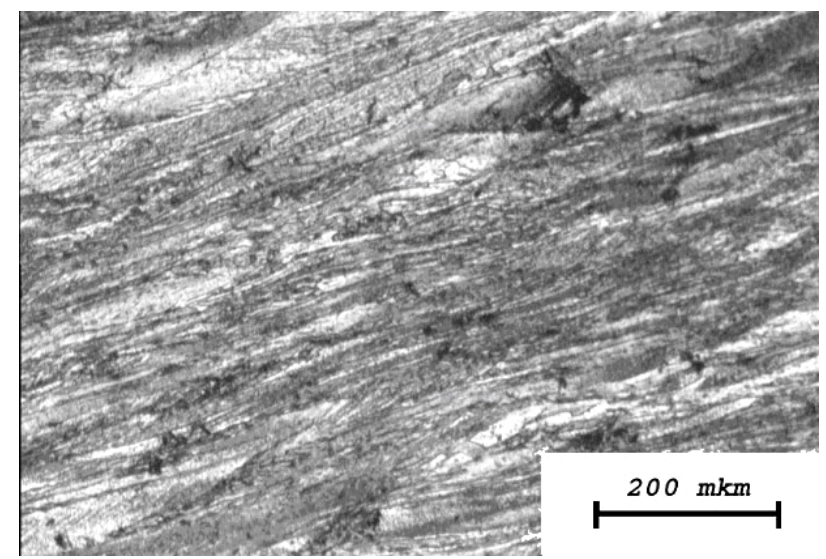

(b)

Fig. 5. Optical metallography of copper structure after ECAP with the standard die-set (a -zone I) and the modified die set (b).

uniform, transformation of the shape of the initial cell abcd with the side $\mathrm{X}$ goes through an intermediate position $a$ 'b c'd into shape a "b" 'c" d". The shear strain in the plane (a two-dimensional variant) $\varepsilon=\cot \alpha$, where $\alpha$ is the angle between the cell and the horizontal axis. In this case it is evident that $\cot \alpha=2 X / X=2$. Hence, $\alpha=26.6^{\circ}$.

In the second case the shear planes fan out for an angle $\Psi=90^{\circ}$ (Fig. $8, \mathrm{~b}$ ). The point b moves along a circle of radius $\mathrm{X}$, not along the square sides as in the first case. Similarly we find $\cot \alpha=(2 \pi X / 4) / X=\pi / 2=1.57$, or $\alpha=32.5^{\circ}$.

These two cases of flow are extreme as they have the maximum and minimum strain values that a given angle of channels intersection can produce, assuming that the local speed of material flow is uniform across the billet section.

Using the grid method, it may be concluded that the material flow in area I for the standard die-set is accurately represented in Fig. 6a. Lower strain in area II does not correspond to any of these pictures. These flow models are idealized. In reality the material flow is influenced by a number of factors, among which friction between deformed material and die-set walls should be singled out as it sets border conditions for the deformation. Its influence is most prominent on the outer part of a billet, where there is contact with the channel walls. Near the inner section of the channel intersection and in the middle part, the contact conditions have little influence with the flow regime being in all cases close to the one predicted by the ideal models.

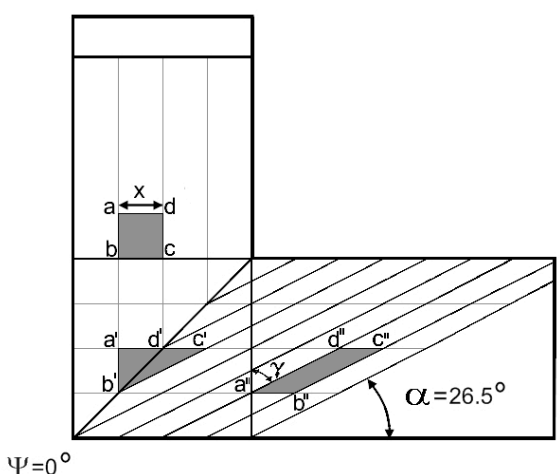

(a)

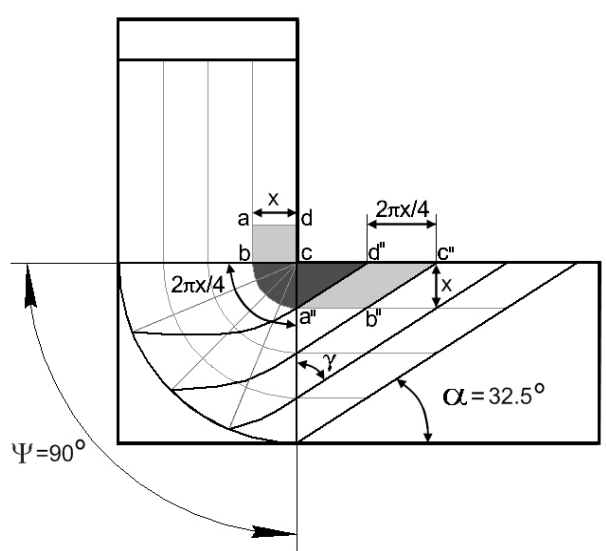

(b)

Fig. 5. Different cases of material flow in the simple shear conditions: a - simple shear (one shear plane $-\mathrm{Y}=0^{\circ}$ ), b - $\mathrm{Y}=90^{\circ}$ ( multitude of shear planes).

A surface obstacle in the output channel in the modified die-set can reduce the applied pressure. The pressure can be employed to increase strain homogeneity during ECAP [16]. The recess in the modified die-set is effective in improving the contact conditions of the external surface of the billet with an output channel wall, as it ensures a simplified shear regime. The observed strain suggests a multitude of intersecting shear planes, which is influenced by the corner of the channels intersection.

Thus, it has been shown that additional straining of the billet lower part can be effected through a constriction of the channel lower part. This resulted in a more homogeneously strained state of the copper billets.

\section{Conclusions}

1. The grid method revealed strain inhomogeneity across copper samples processed with ECAP with the standard die-set. In the lower quarter part of the billet the average strain is significantly lower than in the rest. Correlation between this picture and microstructural changes was observed.

2. With the use of a specially modified die-set where there is a constriction in the output channel, strain remains throughout the sample section. This is validated by the physical modeling data, which completely agree with the observed uniform transformation of a crystalline microstructure accompanied with microhardness increase. 
3. The die-set modification changes in an optimum fashion one of the most important factors that determine plastic flow closer to simple shear, by affecting the contact conditions between the lower outer surface of a sample and the output channel wall in corner of channels intersection.

\section{Acknowledgement}

This work was financially supported by the Ministry of Education and Science of the Russian Federation within the framework of the design part of the state task №11.2540.2014/K

\section{References}

[1] Segal V.M., Reznikov V.I., Kopylov V.I., et al «Processes of structure formation in metals», Minsk, Nauka i tekhnika, 1994, 231 p. (in Russian).

[2] Segal V.M. // Mat. Sci and Eng., 1995, A197, p.157-164.

[3] Valiev R.Z. and Alexandrov I.V. // Bulk Nanostructured Metallic Materials: Production, Structure and Properties (Akademkniga Pub., Moscow, 20 7), p.398. (in Russian).

[4] Valiev R.Z., Islamgaliev R.K., Alexandrov I.V.// Progress in Mat. Sci. 2000, V. 45, pp. 103-189.

[5] Iwahashi Y., Horita Z., Nemoto M. and Langdon T.G. // Acta Mater., 1997, V. 45, №11, pp. 4733-4741.

[6] Andrievskiy R.A., Glezer A.M. // UFN, 2009, V. 179, p. 337-358. (in Russian).

[7] Mishin O.V., Jensen D.J, Hansen N. // Mater. Sci. Eng., 2003, A342, pp. 320-328.

[8] Xu C., Langdon T.G. // Scipta Mater., 2003, V. 48, pp. 1-4.

[9] Shan A., Moon I.G., Ko H.S. and Park J.W.// Scripta Mater., 1999, V. 41, pp. $353-357$.

[10] Suh J.Y., Kim H.S., Park J.W. and Chang J.Y.// Scripta Mater., 2001, V. 44, pp. 677-681.

[11] Kim H.S., Seo M.H., Hong S.I.// Mater. Sci. Eng.. 2000, A 291, pp. 86-90.

[12]Beyerlein I.J., Li S., Necker C.T., Alexander D.J. and Tom C.N.// Phil. Mag. Letters, 2005, V. 85 № 13, pp.1359-1394.

[13]Raab G.I..// Forging and Stamping Production. Material Working by Pressure (FSP. MWP.), 2008, № 11. pp. 20-24. (in Russian).

[14] Raab G.I.. Doctoral dissertation abstract. 2009, p.247. (in Russian).

[15 Beyerlein I.J., Tom C.N. // Mater. Sci. Eng., 2004, A380, pp. 171190.

[16]Lapovok R.E. //Metals, 2004, №1, pp. 44-50. (in Russian). 